\title{
Replacement of Ordinary Portland Cement using Dolomite Powder
}

\author{
K. Sathish Kumar, S. Rajesh, B. Saritha
}

\begin{abstract}
Solid assumes a crucial job in the realm of this paper is a piece of exploratory examination to think about the quality of cement by utilizing incomplete substitution of concrete by dolomite powder.. The dolomite powder is the squashed mineral from dolomite. The substitution paces of bond by dolomite powder are $5 \%, 10 \%$ and $15 \%$ by the greatness of $M 20$ grade concrete. The dolomite powder is mixed in with ordinary bond in the assessment of M20 grade concrete.
\end{abstract}

Keywords - Concrete, Experimental Investigation, M20 Grade.

\section{INTRODUCTION}

Concrete is a versatile engineering material used in most of the Civil Engineering structures. It is basically composed of three components they are cement, water and aggregate[1]. Its noticeably as a crucial building material being developed is a consequence of its economy, awesome durability, ease with which it can be created, the ability to frame it into any shape, size and its high compressive quality.

The Digging of the sand from riverbeds diminishes the water head, so less permeation of water in ground bringing about lower ground water level[2]. Because of this, necessities for more conservative and eco-accommodating waste material have augmented enthusiasm for incomplete

\section{A. Need of Admixture In Concrete}

Admixtures are synthetic concoctions which are added to concrete at the blending stage to change a portion of the properties of the blend. Admixtures ought to never be viewed as a substitute for good blend plan, great workmanship, or utilization of good materials. Admixture used in concrete for reducing the water cement ratio. It improves the workability when used as plasticizer. It gives better appearance and uniformity[3]-[5]. It gives better finishing characteristics. It causes less bleeding and greater pump ability and some retardation of setting times.

\section{MATERIALS AND METHODS}

The material used for partial replacement of concrete are Cement, Fine aggregate, Coarse Aggregate, Dolomite, Copper Slag, Water and Admixture.

Revised Manuscript Received on October 22, 2019.

K. Sathish Kumar, Department of Civil Engineering, Bharath Institute of Higher Education and Research, Chennai, India. Email: sathish_4549@yahoo.co.in

S. Rajesh, Department of Civil Engineering, Bharath Institute of Higher Education and Research, Chennai , India. Email: rajeshskr06@gmail.com

B. Saritha, Department of Civil Engineering, Bharath Institute of Higher Education and Research, Chennai , India. Email: sarichaks@ gmail.com substitution of fine total materials.

\section{A. Cement}

Ordinary Portland cement was used for all concrete mix. The cement was fresh and without lumps. Testing of cement was done as per IS 8112-1989. Ultra Tech cement is used for concrete $\operatorname{mix}[6]-[8]$.

\section{B. Fine Aggregate}

Sand is a normally occurring granular cloth created from finely divided shake and mineral particles. It is portrayed by using size, being advanced to shake and coarser than buildup. Sand can moreover mean a textural class of soil or soil sort; for example an earth containing over eighty five\% sand-sized debris.

\section{Coarse Aggregate}

Normally happening, prepared or produced, inorganic particles in endorsed degree or size range, the littlest size of which will be held on the No. $4(4.76 \mathrm{~mm})$ strainer.

The coarse aggregate is gravel. It is locally available coarse aggregate having the maximum sizes of $6 \mathrm{~mm}$ to $20 \mathrm{~mm}$ were used now in the field. Testing of coarse aggregate done as per IS: $383-1970$. The aggregates which are passed from $20 \mathrm{~mm}$ and retained in $6 \mathrm{~mm}$ sieve size are washed to remove the dust and dirt and were dried to surface dry condition[9]-[11].

\section{Dolomite Powder}

Dolomite is also known as dolostone. The dolomite powder is the crushed mineral from dolostone. The dolomite powder is used to replacement of cement. .Made from particular characteristic rock, it is squashed by a three-phase design comprising of a Jaw Crusher took after by a Cone Crusher lastly a Vertical Shaft Impactor (VSI) to get sand that is reliable in its cubical molecule shapes and degree.
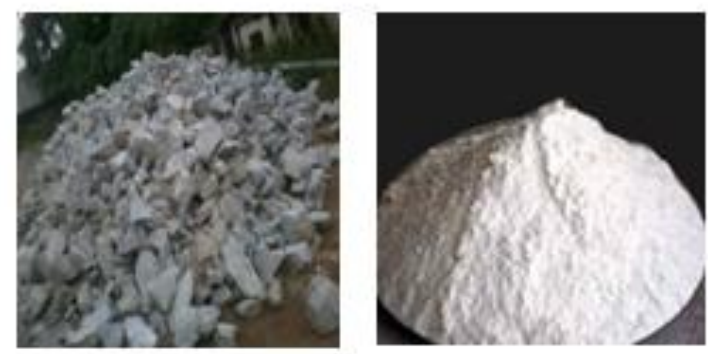

Figure - 1 Dolomite Stone and Powder 


\section{E. MATERIAL PROPERTIES}

\section{Properties of Dolomite}

The chemicals present in dolomite are Carbonate, Calcium Carbonate, Magnesium Carbonate, Insoluble Acid and

Silicon-dioxide.

\section{Chemical Composition}

\begin{tabular}{|c|c|}
\hline CHEMICAL & PERCENTAGE \\
\hline Total Carbonate & $97.4 \%$ \\
\hline $\mathrm{CaC}_{3}$ & $59.5 \%$ \\
\hline MgCo $_{3}$ & $31.9 \%$ \\
\hline Acid Insoluble & $8.7 \%$ \\
\hline $\mathrm{SiO}_{2}$ & $4.1 \%$ \\
\hline
\end{tabular}

\section{METHODOLOGY}

\section{A. Mix Design}

The blend structure strategies being utilized in various nations are for the most part dependent on exact connections, diagrams and charts created from broad trial examinations. An appropriately planned solid blend ought to have least conceivable bond content without yielding quality so as to make in solid blend. A definitive point of deliberating the exclusive houses of the fabric of solid, plastic concrete and solidified cement, is to empower a strong technologist is to plan a solid mixture for a specific quality and solidness.

\section{B. Batching and Mixing}

Gauge Batching was practiced with the assistance of electronic gauging balance. Clustering was done with respect to each the blend extents. Blending was done in plate. It was blended for 2-3 minutes, after the fact than expansion of water.

\section{Placing and Compaction:}

Strong shapes and valuable stone are cleaned and oiled to maintain a strategic distance from the improvement of security among concrete and iron molds. Put the new concrete in molds in 3 layers, squeezing each layer with temper multiple times. The air which is trapped in bond is discharged by table vibrator.

\section{TEST RESULTS AND DISCUSSION}

\section{A. Workability Test}

The expression "workability" is utilized to portray the trouble with where the solid is taken care of, transported or set between the structures .with least loss of homogeneity: the workability of cement is in this manner a composite property.

\section{B. Tests On Hardened Concrete}

Testing of solidified cement assumes a vital part in controlling and affirming the nature of bond solid works. The motivation behind testing solidified cement is to affirming that the required quality of cement is utilized at site. If there should be an occurrence of plan blend concrete, these tests are utilized for checking if the solid has the required target quality for which is planned. The tests that are mostly embraced are pressure test on 3D shapes, Split rigidity on barrel and flexural test on bars.

\begin{tabular}{|l|l|}
\hline$\%$ dolomite powder & Slump value \\
\hline 0 & 118 \\
\hline 5 & 124 \\
\hline 10 & 135 \\
\hline 15 & 110 \\
\hline
\end{tabular}

\section{Compressive Strength}

The compressive strength of concrete were found with various percentage replacement of concrete.

\begin{tabular}{|c|c|c|l|l|}
\hline \multirow{2}{*}{ S1.No } & \multirow{2}{*}{$\begin{array}{c}\% \\
\text { Dolomite } \\
\text { powder }\end{array}$} & \multicolumn{3}{|c|}{$\begin{array}{l}\text { Compression Strength Of } \\
\text { Cubes N/Mm }\end{array}$} \\
\cline { 3 - 5 } & $\begin{array}{l}7 \\
\text { DAYS } \\
\text { N/Mm }\end{array}$ & $\begin{array}{l}14 \\
\text { DAYS } \\
\text { N/Mm }\end{array}$ & $\begin{array}{l}28 \\
\text { DAYS } \\
\text { N/Mm }\end{array}$ \\
\hline 1 & 0 & 14.12 & 17.45 & 22.12 \\
\hline 2 & 5 & 15.14 & 18.34 & 23.15 \\
\hline 3 & 10 & 16.84 & 19.24 & 24.64 \\
\hline 4 & 15 & 13.54 & 15.98 & 18.74 \\
\hline
\end{tabular}

\section{Split Tensile Strength Test}

Computation the material required for get ready cement of given extent. Mix them out and out near to mixing until uniform shade of concrete is gotten. Pour concrete in the oiled with medium consistency oil fill concrete in chamber shape in three layer and crushing each layer with 35 blows consistently appropriated over the surfaces of layer. Following 24 hours of throwing barrel example are topped by flawless bond glue 35 percent water content on topping device following 24 hours the example are drenched into water for definite curing[12].

\begin{tabular}{|c|c|c|c|c|}
\hline \multirow{2}{*}{ S1.Ne } & $\begin{array}{c}\text { \%olomite } \\
\text { powder }\end{array}$ & \multicolumn{3}{|c|}{$\begin{array}{c}\text { Splite tensile Strength Of } \\
\text { Cylinders N/Mm }\end{array}$} \\
\cline { 3 - 5 } & $\begin{array}{c}7 \text { DAYS } \\
\text { N/Mm }\end{array}$ & $\begin{array}{l}14 \\
\text { DAYS } \\
\text { NMm }\end{array}$ & $\begin{array}{l}28 \\
\text { DAYS } \\
\text { NMm }\end{array}$ \\
\hline 1 & 0 & 1.666 & 2.499 & 3.064 \\
\hline 2 & 5 & 1.874 & 2.915 & 3.574 \\
\hline 3 & 10 & 1.743 & 2.622 & 3.212 \\
\hline 4 & 15 & 1.562 & 2.082 & 2.984 \\
\hline
\end{tabular}

\section{CONCLUSION}

In this experiment study, the cubes \& cylinder were casted with the various percentage of dolomite powder $(0 \%, 5 \%$, $10 \%, 15 \%)$ in the concrete.

1. Workability of solid increments when different rates of dolomite powder added to the solid[13].

2. The example threw with OPC+ dolomite powder (10\%) shows the greatest compressive quality when contrasted with ordinary cement $(\mathrm{OPC})[34]$.

3. The example threw with OPC+ dolomite powder $(10 \%)$ shows the greatest rigidity at that point contrasted with every one of the examples. 
Thus, the use of these eco-friendly materials has changed waste into wealth.

\section{REFERENCES}

1. Sathish Kumar, K., Vinothkumar, S., Venkatakrishnaiah, R. \& Mohan, S.J. 2019, "Experimental investigation on rehabilitation of corroded concrete beam specimens", International Journal of Civil Engineering and Technology, vol. 10, no. 1, pp. 2949-2955.

2. Kanchanabhan, T.E., Krishnaiah, R.V., Dayakar, P. and Mani, A., 2019. A detailed study on green building concept in construction industry. International Journal of Civil Engineering and Technology, 10(1), pp. 2944-2948.

3. Mugilvani, P., Murugan, S.T., Kaviya, B. and Sathishkumar, K., 2019. Experimental investigation on nano concrete. International Journal of Civil Engineering and Technology, 10(1), pp. 907-912.

4. Vinothkumar, S., Sathishkumar, K., Anish, C. and Rajesh, S., 2019. Characteristic strength of concrete by partial replacement with sawdust and waste ceramic tiles. International Journal of Civil Engineering and Technology, 10(1), pp. 2821-2829.

5. Chitra, R., Thendral, S., Arunya, A. and Mohan, S.J., 2019. Experimental study on strength of concrete by partial replacement of fine aggregate with saw dust. International Journal of Civil Engineering and Technology, 10(1), pp. 2766-2769.

6. Mani, A., Meikandaan, T.P., Gowrishankar, P.G. and Kanchanabhan, T.E., 2019. A study on treatment of industrial effluent (dyeing) using moringa oleifera, tamarina indica as coagulants. International Journal of Civil Engineering and Technology, 10(1), pp. 2796-2811.

7. Frank Stephen, S., Chockalingam, M.P., Nalanth, N. and Lekshmy Raghavan, P., 2019. Study on the fresh state properties of self compacting concrete modified with recycled concrete aggregate. International Journal of Civil Engineering and Technology, 10(1), pp. 1205-1212.

8. Dayakar, P., Raman, K.V., Arunya, A. and Venkatakrishnaiah, R., 2019. Study on strength properties of sand by biocementation with eggshell. International Journal of Civil Engineering and Technology, 10(1), pp. 2770-2785.

9. Shendge, R.B., Chockalingam, M.P., Saritha, B. and Ambica, A., 2018. Swat modelling for sediment yield: A case study of Ujjani reservoir in Maharashtra, India. International Journal of Civil Engineering and Technology, 9(1), pp. 245-252.

10. Meikandaan, T.P. and Hemapriya, M., 2017. Use of glass FRP sheets as external flexural reinforcement in RCC Beam. International Journal of Civil Engineering and Technology, 8(8), pp. 1485-1501.

11. Harini, A.T., 2017. Experimental study on utilisation of ceramic wastes in concrete. International Journal of Civil Engineering and Technology, 8(8), pp. 1346-1352.

12. Ambica, A., Sartiha, B. and Anbarasan, R., 2017. Groundwater quality assessment using water quality index and GIS, Maduravoyal, Chennai, India. International Journal of Civil Engineering and Technology, 8(8), pp. 1375-1381.

13. Aswathy, M., Saritha, B. and Chockalingam, M.P., 2019. Degradation of anionic dye using Fe/Tio2 composite by photocatalysis. International Journal of Innovative Technology and Exploring Engineering, 8(9 Special Issue 3), pp. 788-791

\section{AUTHORS PROFILE}

K. Sathish Kumar Assistant Professor, Department of Civil Engineering, Bharath Institute of Higher Education and Research, Chennai, India.

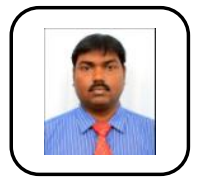

S. Rajesh Assistant Professor, Department of Civil Engineering, Bharath Institute of Higher Education and Research, Chennai , India.

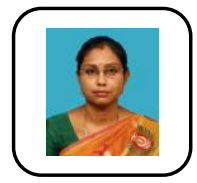

B. Saritha Assistant Professor, Department of Civil Engineering, Bharath Institute of Higher Education and Research, Chennai , India. 